\title{
Expression of Long-Term Adaptation of Synaptic Transmission Requires a Critical Period of Protein Synthesis
}

\author{
Peter V. Nguyen and Harold L. Atwood \\ Department of Physiology, University of Toronto, Toronto, Ontario, M5S 1A8, Canada
}

The crayfish claw closer muscle is innervated by 2 distinct excitatory motoneurons, one tonic and the other phasic. The phasic motoneuron is relatively inactive and generates large EPSPs that normally depress rapidly with repetitive stimulation at moderate frequencies. Stimulation of the phasic motoneuron in vivo for $3 \mathrm{~d}$ at $5 \mathrm{~Hz}(2 \mathrm{hr} / \mathrm{d})$ produced a marked adaptive shift in the neuromuscular synaptic response properties of the motoneuron: average initial EPSPs and depression of EPSPs were significantly reduced. We tested the hypothesis that neuronal protein synthesis is required for full expression of long-term adaptation (LTA). A reversible inhibitor of neuronal protein synthesis, cycloheximide (CHX), was injected into intact crayfish at various times prior to, during, or after each stimulation period. At a dosage of $5 \mu \mathrm{g} /$ gm body weight, $\mathrm{CHX}$ inhibited the incorporation of [ $\left.{ }^{35} \mathrm{~S}\right]-$ methionine into abdominal nerve cord protein for approximately $2 \mathrm{hr}$ after administration (>80\% inhibition). Full expression of LTA was selectively blocked when $\mathrm{CHX}$ was administered $6 \mathrm{hr}$ or $2 \mathrm{hr}$ prior to each stimulation period. Both the reduction in initial EPSP amplitude and the resistance to synaptic depression were significantly attenuated. $\mathrm{CHX}$ administered at the onset of or at the end of each stimulation period did not affect the expression of LTA. Control experiments using unstimulated animals showed that neither chronic nor acute administration of $\mathrm{CHX}$ adversely affected the phasic axon's synaptic response properties. Our results suggest that full expression of neuronal LTA requires the presence of a pool of preexisting, short-lived (or rapidly utilized) protein(s). Depletion of such a pool prior to each stimulation period appears to interfere with subsequent induction of LTA.

The crustacean neuromuscular junction provides a highly suitable preparation for the precise study of mechanisms of synaptic plasticity (for review, see Atwood and Wojtowicz, 1986). Specifically, the phasic ("fast") excitatory motoneuron of the crayfish claw (Van Harreveld and Wiersma, 1936) provides an identi-

\footnotetext{
Received June 16, 1989; revised Aug. 14, 1989; accepted Sept. 14, 1989.

This work was supported by grants (to H.L.A.) from the MRC (Canada) and NSERC (Canada). We thank Dr. G. A. Lnenicka, of SUNY-Albany, for his guidance during the early phases of this work and Drs. A. A. Horner and M. Vranic, of the University of Toronto, for the use of their spectrophotometer. Critical input from Drs. U. DeBoni, A. J. Mercier, P. Pennefather, and M. Wojtowicz of the Department of Physiology, University of Toronto, is gratefully acknowledged. Technical assistance and help in preparing the manuscript were provided by Marianne Hegström-Wojtowicz. P.V.N. was supported by an NSERC Postgraduate Scholarship and a University of Toronto Connaught Scholarship.

Correspondence should be addressed to Peter Nguyen at the above address.
}

Copyright (C) 1990 Society for Neuroscience $0270-6474 / 90 / 041099-11 \$ 02.00 / 0$ fiable neuron capable of displaying several forms of stimulationinduced modifications of synaptic transmission, including lowfrequency depression, long-term facilitation (Pahapill et al., 1987), and long-term adaptation (Lnenicka and Atwood, 1985a, b).

In general, crustacean motoneurons may be differentially classified as phasic or tonic according to their natural patterns of activity (Atwood, 1973). Phasic motoneurons are silent most of the time, while tonic motoneurons fire frequently and intermittently (Atwood, 1973). The neuromuscular synapses of crustacean motoneurons are also sharply segregated in their physiological response characteristics. Neuromuscular synapses of phasic motoneurons generate large initial EPSPs that depress rapidly with repeated activation, while those of tonic motoneurons generate small EPSPs that facilitate and are resistant to depression during repeated activation (Atwood, 1976).

Previous studies have shown that the physiological and morphological properties of the neuromuscular synapses of the phasic motoneuron of the crayfish claw closer muscle are shifted toward a more tonic profile by chronic stimulation of the phasic axon via electrodes implanted in vivo (Lnenicka and Atwood, $1985 \mathrm{a}, \mathrm{b})$. Thus, artificial imposition of a tonic pattern of activity on a phasic motoneuron induced a series of adaptive changes. Physiological changes included reduction in initial transmitter release and enhanced resistance to depression of transmitter release during repetitive test stimulation of the phasic axon (Lnenicka and Atwood, 1985a, b). Morphologically, the normally slender, filiform terminal processes of the phasic motoneuron became more varicose and thus more similar to the terminals of the tonic excitatory motoneuron innervating the same muscle (Lnenicka et al., 1986). Furthermore, intraterminal mitochondria were significantly increased in volume in chronically stimulated motoneurons, a characteristic that might contribute to their resistance to synaptic depression (Lnenicka et al., 1986). Collectively, these activity-induced changes in synaptic and morphological properties of a phasic motoneuron constitute "long-term adaptation" (LTA) to imposed activity; the physiological adaptation can last for at least $10 \mathrm{~d}$ following prolonged stimulation (Lnenicka and Atwood, 1985a).

The morphological changes associated with LTA, its persistence over several days, and the failure to induce LTA in deccntralizcd motoneurons (Lnenicka and Atwood, 1985b) all suggest that expression of LTA may involve changes in protein synthesis within the cell body of the phasic motoneuron. Quantitative changes in the synthesis of preexisting proteins, and/or the de novo synthesis of novel proteins, could be prerequisite(s) for the expression of LTA. Such modifications of neuronal gene 
expression are likely triggered by depolarization of the phasic motoneuron, a condition that by itself is sufficient to fully induce LTA (Lnenicka and Atwood, 1988).

The objective of the present study was to ascertain whether the full expression of LTA involved changes in protein synthesis occurring before, during, or after each stimulation period. Activity-induced changes in protein synthesis have been implicated in the expression of various forms of long-term synaptic plasticity, including long-term sensitization in Aplysia (Montarolo et al., 1986; Dale et al., 1987; Castellucci et al., 1988, 1989; Schacher et al., 1988), and mammalian hippocampal longterm potentiation (Stanton and Sarvey, 1984; Deadwyler et al., 1987; Sarvey, 1988). Since there is currently no satisfactory in vitro model of LTA in crayfish, our experimental strategy entailed the injection of cycloheximide (CHX), a reversible inhibitor of somal translation (Wettstein et al., 1964; Sisler and Siegel, 1967), into intact crayfish before, during, or after each stimulation period. The extent of inhibition of protein synthesis was determined by measuring rates of $\left[{ }^{35} \mathrm{~S}\right]$-methionine incorporation into abdominal nerve cords of injected animals. Two days following periodic in vivo stimulation of the phasic motoneuron of the claw, we measured EPSPs (generated by the phasic motoneuron) by recording intracellularly from fibers of the claw closer muscle. We report that although CHX, at the dosages used here, did not deleteriously affect baseline neuromuscular transmission when administered chronically or acutely to unstimulated animals, CHX did selectively prevent full expression of LTA in stimulated animals when administered $6 \mathrm{hr}$ or $2 \mathrm{hr}$ prior to each stimulation period. Maximal inhibition of protein synthesis during or soon after each stimulation period did not affect full expression of LTA. The implications of these results in light of previous work on neuromuscular LTA are discussed.

\section{Materials and Methods}

Animals. Since LTA is expressed most reliably in young crayfish (Lnenicka and Atwood, 1985a), all experiments were performed on crayfish (Procambarus clarkii) with carapace lengths of $2.0-3.0 \mathrm{~cm}$, bilaterally symmetrical claw lengths of $0.8-1.5 \mathrm{~cm}$, and weights of approximately $2.8-4.0 \mathrm{gm}$. Their estimated ages were $6-8$ months. Following reception from a supplier in Louisiana (Atchafalaya Co.), animals were maintained in dechlorinated tap water at $16^{\circ} \mathrm{C}$ and were fed carrots and fishmeal pellets weekly. All LTA experiments were performed in late winter and early spring.

Materials. CHX was obtained from Sigma Chemical Co. (St. Louis, MO) and was dissolved in Van Harreveld's solution (Van Harreveld, 1936) buffered at pH 7.4 with 0.1 M HEPES. $\left[{ }^{35} \mathrm{~S}\right]-$ methionine $\left(\left[{ }^{35} \mathrm{~S}\right]-\right.$ Met) was obtained from ICN Inc. as an aqueous solution containing $85 \%\left[{ }^{35} \mathrm{~S}\right]-$ Met, $15 \%\left[{ }^{35} \mathrm{~S}\right]$-cysteine, and $10 \mathrm{~mm} 2$-mercaptoethanol. The original supply $(10 \mathrm{mCi} / \mathrm{ml})$ was diluted to $1 \mu \mathrm{Ci} / \mu \mathrm{l}$ by addition of crayfish saline and stored at $-80^{\circ} \mathrm{C}$.

Measurement of [ ${ }^{35}$ S]-methionine incorporation into proteins in abdominal nerve cords. Abdominal nerve cords were used for their relative ease of extraction and accessibility. Measurements of amino acid incorporation into abdominal nerve cords probably are representative of similar incorporation into whole nerve cords.

The level of protein synthesis inhibition in abdominal nerve cords was measured by incorporation of [ $\left.{ }^{35} \mathrm{~S}\right]-\mathrm{Met}$ into TCA-precipitable macromolecules. CHX, at a dosage of $1 \mu \mathrm{g} / \mathrm{gm}, 5 \mu \mathrm{g} / \mathrm{gm}$, or $10 \mu \mathrm{g} / \mathrm{gm}$, was injected into live crayfish using a 100- 1 Hamilton syringe fitted with a 26-gauge needle. Animals received injections at the ventral surface of the first abdominal segment, lateral to the nerve cord. Stock solutions of $\mathrm{CHX}$ were prepared at the following concentrations for the three dosages: $0.1 \mathrm{mg} / \mathrm{ml}$ for $1 \mu \mathrm{g} / \mathrm{gm}$ dosage, $0.5 \mathrm{mg} / \mathrm{ml}$ for $5 \mu \mathrm{g} / \mathrm{gm}$ dosage, and $1.0 \mathrm{mg} / \mathrm{ml}$ for $10 \mu \mathrm{g} / \mathrm{gm}$ dosage. Injected volumes were approximately $4 \%$ of each animal's estimated total body fluid volume. Control animals received equivalent dosimetric volumes of crayfish saline. $\left[{ }^{35} \mathrm{~S}\right]-$ Met $(12 \mu \mathrm{Ci} / \mathrm{gm})$ was injected into control and drug-treated animals 1 hr prior to sacrifice and extraction of nerve cords. Animals received isotope injections at the same site as the $\mathrm{drug} /$ saline injection; volumes of injected isotope were approximately $4.5 \%$ of each animal's total body fluid volume. Each animal was maintained thereafter in separate moistened Styrofoam cups.

Abdominal nerve cords were extracted at selected times after $\mathrm{CHX}$ / saline injection. Crayfish were killed by thoracic hemisection and decapitation, while leaving intact the abdominal segments. The abdomen was pinned ventral side up in a Petri dish lined with Sylgard and containing crayfish saline. The integument was carefully cut away, exposing the underlying abdominal nerve cord with 6 inlact ganglia (Fig. 1). Each nerve cord was bisected to form 2 longitudinal hemicords, each consisting of 3 intact, interconnected ganglia. Care was taken to exclude extraneous muscle tissue in the samples. Each hemicord furnished a single measurement; thus, each animal yielded 2 separate measurements of $\left.{ }^{35} \mathrm{~S}\right]-\mathrm{Met}$ incorporation. All sample sizes were expressed as numbers of animals.

Each hemicord was manually homogenized in $50 \mu$ of ice-cold 0.1 $\mathrm{M}$ HFPFS and transferred, via 5 successive $100-\mu \mathrm{l}$ rinses with $0.1 \mathrm{M}$ HEPES, to a capped centrifuge tube. Tubes were spun in a tabletop centrifuge (Fisher Scientific) at $800 \times \mathrm{g}$ for $10 \mathrm{~min}$, and $100 \mu \mathrm{l}$ of the supernatant were transferred to a separate microfuge tube for subsequent quantitative protein assay; $400 \mu$ l of the remaining supernatant in each tube were transferred to a new tube. To this sample were added $200 \mu \mathrm{l}$ of BSA $(1 \mathrm{mg} / \mathrm{ml})$ and $600 \mu \mathrm{l}$ of $20 \%(\mathrm{wt} / \mathrm{vol}) \mathrm{TCA}$. The mixture was vortexed and spun at $800 \times g$ for 10 min, after which the supernatant was discarded and the remaining pellet washed with $1 \mathrm{ml}$ of $10 \%$ TCA. Each tube was again centrifuged at $800 \times g$ for $10 \mathrm{~min}$ and the $10 \%$ TCA wash-spin cycle repeated twice for each tube, giving a total of 3 washes with $10 \%$ TCA. All supernatant was discarded.

Following the washes, $500 \mu \mathrm{l}$ of $1 \mathrm{M} \mathrm{KOH}$ were added to each centrifuge tube to dissolve the pellet. Each tube was vortexed and $450 \mu \mathrm{l}$ of the mixture were transferred to individual scintillation vials; $20 \mathrm{ml}$ of aqueous counting scintillant (Amersham Corp.) were added to each vial. Blanks were prepared for measurement of background activity. Counts were run on a ${ }^{14} \mathrm{C}$-program, since the maximum emitted energy from $\left[{ }^{35} \mathrm{~S}\right]$ is almost identical to that of $\left[{ }^{14} \mathrm{C}\right]$ (Freifelder, 1982). Each vial was counted for $2 \mathrm{~min}$ in a scintillation counter (Tracer Mark III 6881). The count obtained from each vial represented the amount of TCA-precipitable [ ${ }^{35}$ S]-activity incorporated into one hemicord. Since $\left.{ }^{[3 S} \mathrm{S}\right]-\mathrm{Met}$ is incorporated into proteins, the counts may essentially be regarded as proportionate measures of the amount of TCA-precipitable protein formed (Freifelder, 1982).

Counts were normalized for time-dependent variations in the amount of protein formed. The amount of protein per hemicord was estimated by the Bradford protein microassay (Bradford, 1976). One milliliter of Bradford reagent was added to $100 \mu \mathrm{l}$ of supernatant extracted from each centrifuge tube (see above). The absorbance at $595 \mathrm{~nm}$ was measured on a Beckman DB-G spectrophotometer. The amount of protein was determined by interpolation on a standard curve prepared from absorbance measurements of known quantities of BSA. All counts were expressed as $\mathrm{cpm} / \mu \mathrm{g}$ protein and were adjusted for background and decay. Percentage inhibition of $\left[{ }^{3} \mathrm{~S}\right]$-Met incorporation by $\mathrm{CHX}$ was calculated by comparing incorporation in drug-treated hemicords with that in saline-treated hemicords.

\section{Electrophysiological experiments}

Induction of $L T A$. As described previously by Lnenicka and Atwood (1985a), LTA was induced in the phasic motoneuron of the claw by stimulation through a pair of Teflon-coated stainless-steel wires (Medwire Corp.) implanted in the carpopodite of the claw. A more distal pair of electrodes of the same material was implanted in the propodite for recording of myograms from the closer muscle. The myograms produced by the phasic axon of the closer muscle were monitored to ensure that stimulation of the axon occurred throughout the stimulation period (Lnenicka and Atwood, 1985a). The contralateral claw of each animal was used as an unstimulated control.

Chronic stimulation was applied at $5 \mathrm{~Hz}$ for $2 \mathrm{hr} / \mathrm{d}$ for 3 consecutive days. Pulse duration was adjusted during stimulation to maintain recruitment of the phasic axon, while taking care not to induce autotomy. Two days following the last stimulation period, claws were isolated for intracellular recording of EPSPs. Animals were maintaincd in separate water-filled cups between stimulation periods.

Intracellular recording of EPSPS from the closer muscle. Dissection of isolated claws and intracellular recording of EPSPs were carried out exactly as described by Lnenicka and Atwood (1985a). Conventional 
intracellular recording techniques were employed, using glass microelectrodes filled with $3 \mathrm{M} \mathrm{KCl}$ and having tip resistances of 10-20 megohms. The lateral region of a single distal fiber of the closer muscle was impaled, since the distal fibers are most strongly innervated by the phasic axon (Lnenicka and Atwood, 1985b). Saline temperature was maintained at $18^{\circ} \mathrm{C}$; no perfusion was necessary since stable EPSP recordings could be maintained during these brief recording sessions (Lnenicka and Atwood, 1985a, b). Since EPSPs produced by the phasic axon are very large (10-25 mV) during low-frequency stimulation, there was no difficulty in confirming that the phasic axon had been recruited. All EPSP amplitudes were corrected for nonlinear summation (Martin, 1955), assuming a reversal potential of $+11.5 \mathrm{mV}$ (Onodera and Takeuchi, 1975).

The initial EPSP was determined for each claw by averaging 8 successive EPSPs elicited by $0.01 \mathrm{~Hz}$ stimulation of the phasic axon. Averaging was performed on-line by a digital storage oscilloscope (SonyTektronix 336).

As a test for synaptic depression, the phasic axon was then stimulated continuously at $5 \mathrm{~Hz}$ for $30 \mathrm{~min}$, while EPSP amplitudes were measured every $5 \mathrm{~min}$ through on-line averaging of 16 successive EPSPs per time point.

Drug control experiments. In a number of separate experiments, dissected unstimulated claws were presoaked in $0.6 \mathrm{~mm}$ CHX for $30 \mathrm{~min}$ at $18^{\circ} \mathrm{C}$. After this presoak, the following stimulation protocol was applied to each claw's phasic axon, in successive stages (after Pahapill et al., 1987): (1) determination of initial EPSP amplitude $(0.01 \mathrm{~Hz}) ;(2)$ stimulation at $0.1 \mathrm{~Hz}$ for $5-10 \mathrm{~min}$, thereby eliciting low-frequency depression (LFD); (3) stimulation at $5 \mathrm{~Hz}$ for $30 \mathrm{~min}$, eliciting highfrequency depression (HFD); (4) resumption of $0.1 \mathrm{~Hz}$ stimulation to test for long-term facilitation (LTF). Identical experiments were performed on saline-presoaked claws. An unpaired Student's $t$ test was used to compare EPSP amplitudes measured under these conditions. These experiments served as tests for harmful effects of peripherally applied $\mathrm{CHX}$ on baseline neuromuscular transmission. The $0.6-\mathrm{mm}$ concentration of $\mathrm{CHX}$ was approximately 10 times that calculated to exist in vivo following equilibration of a single injection of $5 \mu \mathrm{g} / \mathrm{gm}$ CHX.

In a second series of experiments, CIIX $(5 \mu \mathrm{g} / \mathrm{gm})$ was injected into unstimulated crayfish once each day for 3 consecutive days. Two days following the last injection, claws were removed for recording of EPSPs using the previously described stimulation protocol. Saline-injected animals served as controls. Since intact animals were used, these experiments served as tests for harmful side effects of repeated, acute periods of protein synthesis inhibition on neuromuscular transmission. The injection regimen was identical to that used for all subsequent experiments on LTA expressison. All animals were maintained in separate water-filled containers.

Effects of protein synthesis inhibition on expression of LTA. Crayfish were divided into 4 groups, designated according to the time of injection of $\mathrm{CHX}(5 \mu \mathrm{g} / \mathrm{gm})$ relative to initiation of chronic stimulation. Animals in the " $-6 \mathrm{hr}$ " group received injections $6 \mathrm{hr}$ prior to stimulation. Animals in the " $-2 \mathrm{hr}$ " group reccived injections $2 \mathrm{hr}$ prior to each stimulation period, while those in the " $0 \mathrm{hr}$ " group received injections at the onset of stimulation. Finally, animals in the " $2 \mathrm{hr}$ " group received injections at the end of stimulation. A fifth group, henceforth referred to as the "control group," received saline injections instead of CHX Animals within each group received single injections at a single prescribed time on each day of chronic stimulation. All were stimulated using the regimen described previously. Animals were maintained in separate water-filled containers between stimulation trials.

Statistical treatment of electrophysiological data. The change in initial (or final) EPSP amplitude resulting from chronic stimulation was calculated for each animal as the difference between the initial (or final) EPSP amplitude of the stimulated ("experimental") claw and that of the contralateral unstimulated ("control") claw. Mean changes were calculatcd by averaging all differences within each of the 4 drug-treated groups. These mean changes were compared with the corresponding mean changes of the control group, using an unpaired Student's $t$ test. Comparisons of raw initial and final EPSP amplitudes of experimental and control claws within each group of animals were also performed using a paired $t$ test.

Additionally, a depression index was calculated for each claw:

$$
\text { Depression index }=1-\frac{\text { final EPSP amplitude }}{\text { initial EPSP amplitude }}
$$

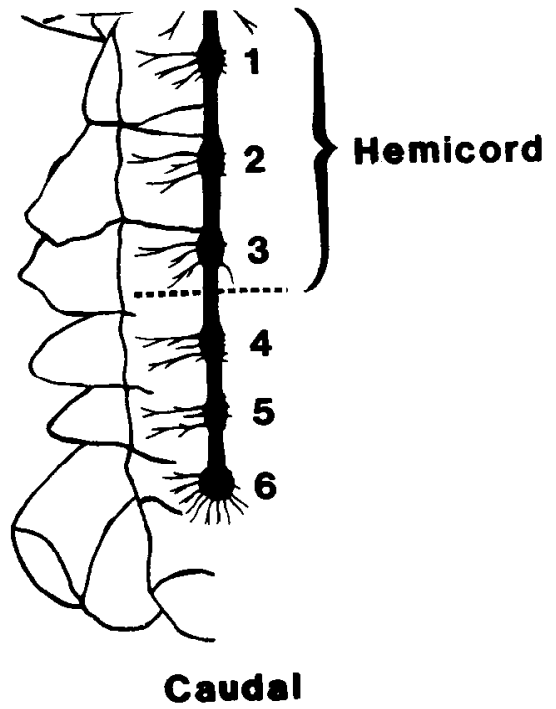

Figure 1. Crayfish abdominal nerve cord. Following injection of $\left[{ }^{35} S\right]-$ Met into intact crayfish, abdominal nerve cords were extracted and bisected to form 2 congruent hemicords, each with 3 interconnected ganglia. Each hemicord yielded a single count of incorporated activity.

This depression index is proportional to synaptic depression. For claws that displayed net facilitation, with final EPSP amplitude greater than initial EPSP amplitude, an index value of zero was assigned. Mean depression indices were calculated for control and experimental claws within each drug-injected group and compared with those of the control group, using an unpaired $t$ test.

\section{Results}

\section{Inhibition of $\left[{ }^{35} S\right]-$ Met incorporation by cycloheximide}

We determined the extent of inhibition of $\left[{ }^{35} \mathrm{~S}\right]-\mathrm{Met}$ incorporation into neural tissue by $\mathrm{CHX}$ by injecting different dosages of CHX into intact crayfish and extracting their abdominal nerve cords at various times postinjection.

For all dosages tested, inhibition of [ $\left.{ }^{35} \mathrm{~S}\right]-$ Met incorporation recovered fully by $16 \mathrm{hr}$ after a single CHX injection (Fig. $2 A$ ). The range of sample sizes was $n=3$ to $n=6$ animals ( 2 hemicords/animal) per time point for the 3 dosages tested. Each animal furnished 2 counts of incorporated activity. The mean count measured from saline-treated, rostral hemicords (130 \pm $16 \mathrm{cpm} / \mu \mathrm{g} \mathrm{SEM} ; n=30$ hemicords) was not significantly different from that measured from saline-treated caudal hemicords $(157 \pm 25 \mathrm{cpm} / \mu \mathrm{g} ; n=28, p>0.2$ for an unpaired $t$ test $)$. Similarly, there were no significant differences between counts measured from rostral and caudal hemicords in each of the 3 $\mathrm{CHX}$-injected groups.

At a dosage of $1 \mu \mathrm{g} / \mathrm{gm}, \mathrm{CHX}$ only transiently inhibited $\left[{ }^{35} \mathrm{~S}\right]-$ Met incorporation into nerve cords, with peak inhibition occurring at $1 \mathrm{hr}$ post-CHX $(91 \pm 1 \% \mathrm{SEM})$ and receding to 71 $\pm 7 \%$ at $2 \mathrm{hr}$ post-CHX (Fig. $2 A$ ). This dosage was considered unsuitable for our experiments on LTA expression, since the duration of maximal inhibition was too brief.

At $10 \mu \mathrm{g} / \mathrm{gm}, \mathrm{CHX}$ suppressed incorporation maximally for at least $5 \mathrm{hr}$ post-CHX, with the level of inhibition remaining greater than $80 \%$ up to $6 \mathrm{hr}$ post-CHX (Fig. $2 A$ ). This prolonged suppression of incorporation following a single injection was also deemed unsuitable, since the duration of maximal inhibition far exceeded the duration of each chronic stimulation period $(2 \mathrm{hr})$. Furthermore, the prolonged inhibition may also induce 

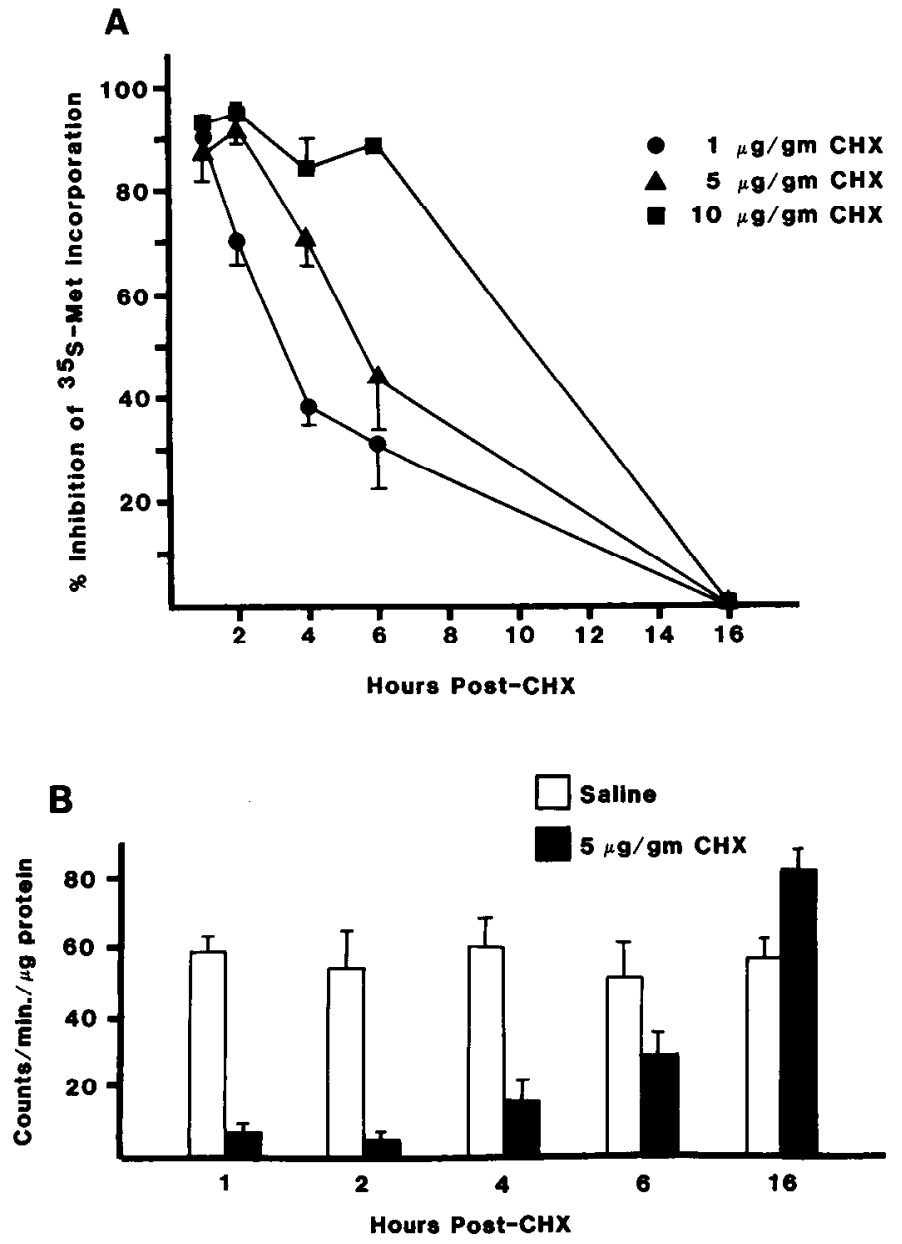

Figure 2. Time course of protein synthesis inhibition by cycloheximide (CHX). $A$, Percentage inhibition of protein synthesis by $\mathrm{CHX}$ is dosedependent. Inhibition was measured from counts of incorporated $\left[{ }^{35} \mathrm{~S}\right]-$ Met activity in abdominal nerve cords. Each point represents the mean of 3-6 animals. Bars represent SEM. $B$. Counts of incorporated $\left.{ }^{35} \mathrm{~S}\right]-$ Met activity in saline- and CHX-treated hemicords, for $5 \mu \mathrm{g} / \mathrm{gm} \mathrm{CHX}$. Inhibition of protein synthesis was maximal for approximately $2 \mathrm{hr}$ following a single $\mathrm{CHX}$ injection and was fully reversed by $16 \mathrm{hr}$ post$\mathrm{CHX}$. This dosage of CHX was used for all experiments on long-term adaptation. Six animals were assayed for each time point ( 3 for saline and 3 for $\mathrm{CHX}$ )

long-lasting adverse side effects, which may be amplificd following repeated daily injections of $\mathrm{CHX}$. The potential for cumulative toxicity resulting from repeated $\mathrm{CHX}$ injections cannot be ignored, especially since we used a chronic stimulation regimen that spans several days.

Following injection of $5 \mu \mathrm{g} / \mathrm{gm} \mathrm{CHX}$, incorporation was inhibited by greater than $85 \%$ for approximately $2 \mathrm{hr}$ post-CHX (Fig. 2, $A, B$ ). Peak inhibition occurred at $2 \mathrm{hr}$ post-CHX (92 $\pm 1 \%$ ), with the level at $1 \mathrm{hr}$ post-CHX being $88 \pm 3 \%$. The inhibition dropped to $74 \pm 7 \%$ at $4 \mathrm{hr}$ post-CHX. Thus, $5 \mu \mathrm{g} /$ gm CHX was used for all subsequent experiments on LTA expression (including drug control experiments), since its duration of maximal inhibition closely matched the duration of each stimulation period. This criterion allowed a direct test of the hypothesis that protein synthesis during each stimulation period may be required for LTA expression.

The level of incorporation at $16 \mathrm{hr}$ post-CHX was greater in $\mathrm{CHX}$-treated hemicords than in saline controls (Fig. 2B). This elevation was evident for all dosages tested and may have resulted from a postrecovery acceleration of protein synthesis subsequent to the translation of a pool of mRNA accumulated during translational inhibition by CHX ( $c f$. Montarolo et al., 1986, for anisomycin data).

Overall, $\mathrm{CHX}$ produced a reversible, dose-dependent inhibition of $\left.{ }^{35} \mathrm{~S}\right]-\mathrm{Met}$ incorporation into abdominal nerve cords. Such inhibition presumably occurs at the translational stage of protein synthesis (Wettstein et al., 1964; Sisler and Siegel, 1967), although we cannot confirm this under our conditions. Furthermore, the observed inhibition represented the net sum of inhibition occurring in both neuronal and glial elements associated with abdominal nerve cords.

\section{Effects of $C H X$ on EPSPs in isolated naive claws}

Numerous protein synthesis inhibitors have been shown to produce rapid depression of evoked EPSPs when applied peripherally to isolated nerve-muscle preparations at millimolar concentrations (Onodera and Takeuchi, 1977). Such effects were attributed to interference with postsynaptic ionic conductances, in a manner independent of protein synthesis inhibition (Onodera and Takeuchi, 1977). We tested for detrimental effects of $\mathrm{CHX}$ on neuromuscular transmission in the claw closer muscle. Unstimulated claws were dissected, then preincubated in 0.6 mM CHX for $30 \mathrm{~min}$. This concentration was approximately 10-fold higher than that calculated to cxist in vivo following a single injection of $5 \mu \mathrm{g} / \mathrm{gm} \mathrm{CHX}$ (assuming uniform distribution of drug in the body fluids).

Stimulation of the phasic axon at $0.01 \mathrm{~Hz}$ produced an average initial EPSP amplitude of $21.5 \pm 1.3 \mathrm{mV}$ in CHX-incubated claws (Fig. $3 A, n=10$ ). This amplitude was not significantly different from that of saline-incubated claws $(23.5 \pm 0.5 \mathrm{mV}$, $n=7, p>0.05$ ). Subsequent stimulation at $0.1 \mathrm{~Hz}$ elicited an LFD (Fig. $3 A$ ) of EPSPs that is characteristic of the phasic claw motoneuron (Pahapill et al., 1987). No observable differences in either the time course or magnitude of LFD were evident in the 2 claw groups (Fig. $3 \mathrm{~A}$ ). Stimulation at $5 \mathrm{~Hz}$ for $30 \mathrm{~min}$ produced an initial transient facilitation followed by rapid depression (HFD) of EPSPs (Fig. 3A). Final EPSPs measured after $30 \mathrm{~min}$ of $5 \mathrm{~Hz}$ stimulation were not significantly different in amplitude between the 2 claw groups ( $p>0.05$; Fig. 3, $A$, $B$ ). Resumption of $0.1 \mathrm{~Hz}$ stimulation revealed an LTF of EPSPs (Pahapill et al., 1987) (Fig. 3, $A, B$ ). Both the magnitude and the time course of LTF in CHX-treated claws did not significantly differ from those of saline-treated claws $(p>0.05)$.

It appears that $0.6 \mathrm{~mm}$ CHX, under the conditions employed here, did not exert any observable detrimental effects on EPSP amplitudes and waveforms, and on the time course and magnitudes of LFD, IIFD, and LTF. Peripherally applied CHX appears to have minimal side effects on the transmitter-releasing capacity of the phasic motoneuron. These results appear to rule out significant harmful side effects of acutely administered CHX on activity-dependent neuromuscular transmission in the phasic claw motoneuron.

\section{Effects of repeated $C H X$ injections on evoked EPSPS}

We tested for possible harmful side effects of repeated injections of CHX on evoked EPSPs in the claw's phasic motoneuron. Intact crayfish $(n=4)$ with symmetrical unstimulated claws were injected with $5 \mu \mathrm{g} / \mathrm{gm} \mathrm{CHX}$ once per day for 3 consecutive days. Claws were isolated $2 \mathrm{~d}$ after the last injection for intra- 


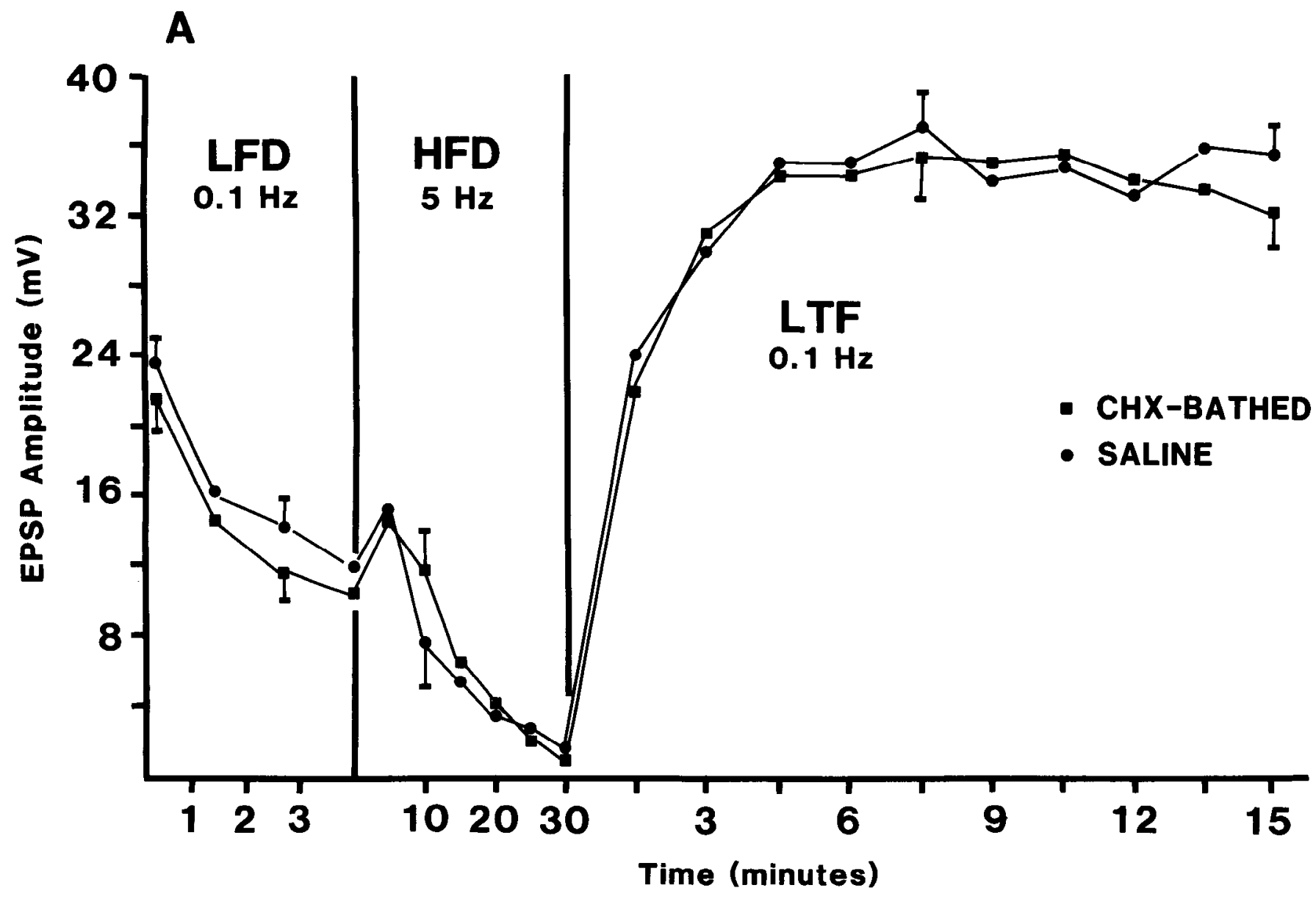

B

SALINE

0 min

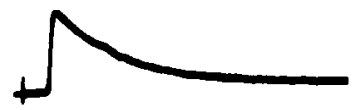

30

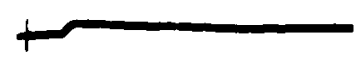

5

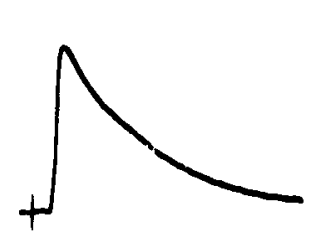

\section{$5 \mathrm{~Hz}$}

CHX
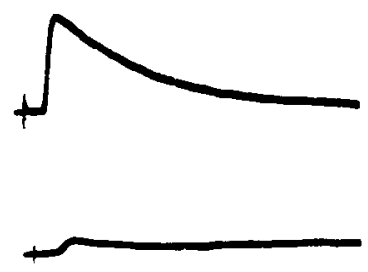

$0.1 \mathrm{~Hz}$

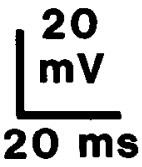

Figure 3. CHX incubation controls. A. Isolated unstimulated claws were incubated in $0.6 \mathrm{~mm}$ CHX for 30 min prior to intracellular recording of EPSPs evoked by stimulation of the closer muscle's phasic axon. CHX had no effect on the time course and magnitude of low-frequency depression $(L F D)$, high-frequency depression $(H F D)$, and long-term facilitation $(L T F)$ in CHX-incubated claws $(n=10)$ as compared to salineincubated controls $(n=7)$. Bars represent SEM. B, Representative EPSP traces from CHX- and saline-incubated claws obtained from 2 separate animals. CHX had no effect on the waveforms of EPSPs evoked before $(0 \mathrm{~min})$ and after $(30 \mathrm{~min}) 5 \mathrm{~Hz}$ stimulation of the phasic axon. EPSPs evoked at $0.1 \mathrm{~Hz} 5 \mathrm{~min}$ after $5 \mathrm{~Hz}$ stimulation were unaffected by CHX; LTF was evident from the larger amplitudes of these EPSPs, as compared to the initial amplitudes prior to $5 \mathrm{~Hz}$ stimulation. 
Figure 4. CHX injection controls. Intact unstimulated crayfish were injected with $5 \mu \mathrm{g} / \mathrm{gm} \mathrm{CHX}$ once per day for 3 consecutive days, and EPSPs recorded from the claw closer muscle $2 \mathrm{~d}$ thereafter. No observable effects on LFD, HFD, and LTF were evident (see Fig. 3). $n=4$ animals for each group.

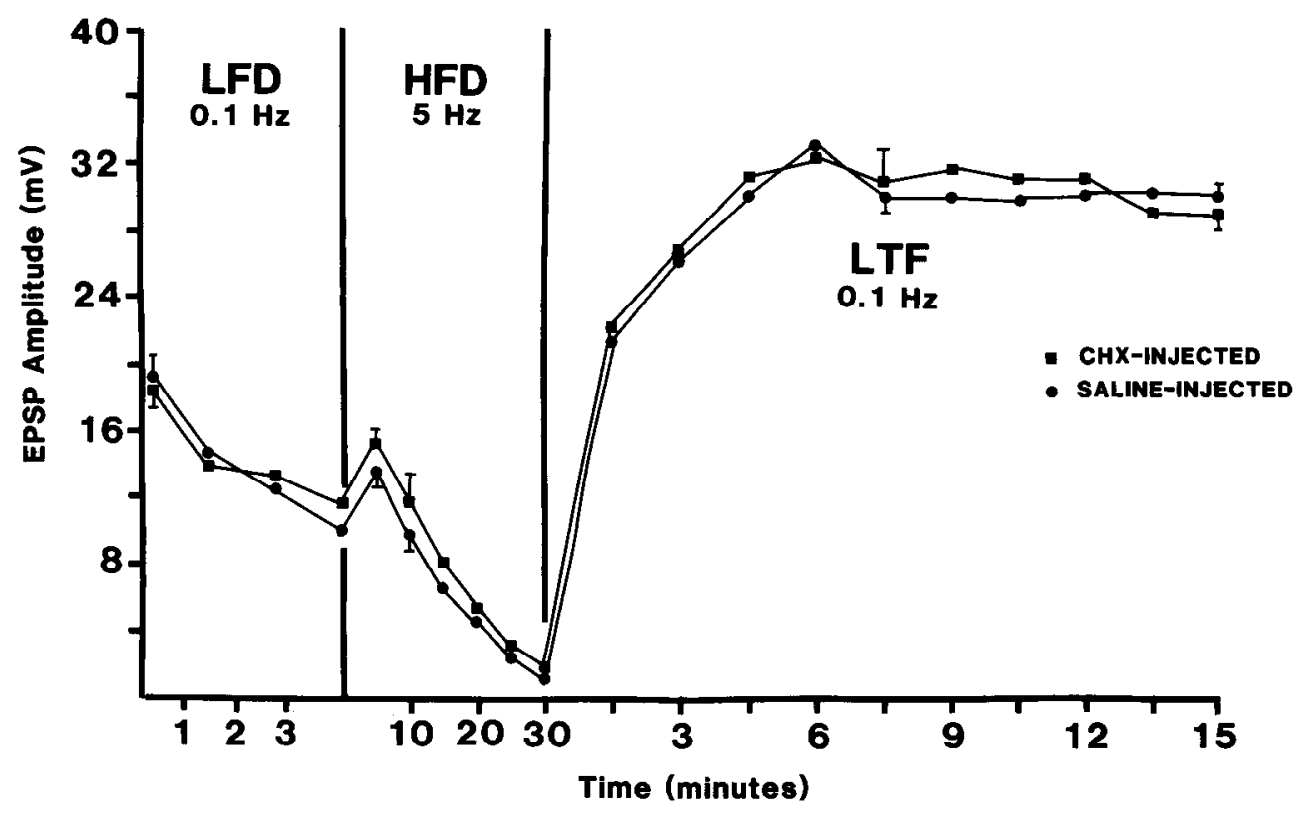

cellular EPSP recordings. A second group of saline-injected animals served as controls $(n=4)$.

The stimulation protocol was the same as described above for the CHX incubation controls. The mean initial EPSP amplitude in $\mathrm{CHX}$-injected animals was $18.7 \pm 1.3 \mathrm{mV}$. This was not significantly different from the mean initial amplitude measured in saline-injected controls (19.2 $\pm 1.1 \mathrm{mV}, p>0.05$; Fig. 4). Mean final EPSP amplitudes measured after $30 \mathrm{~min}$ of $5 \mathrm{~Hz}$. stimulation were also not significantly different between the 2 groups $(p>0.05 ;$ Fig. 4$)$. Furthermore, neither the time courses nor the magnitudes of LFD, HFD, and LTF were significantly different between the 2 groups ( $p>0.05$ for all points in Fig. 4).

These results indicate that repeated bouts of acute protein synthesis inhibition did not produce any observable side effects on neuromuscular transmission under the conditions employed

Table 1. Summary of mean EPSP amplitudes in control and CHXinjected groups of animals

\begin{tabular}{cll} 
& $\begin{array}{l}\text { Mean initial/mean final EPSP } \\
\text { (mV } \pm \text { SEM) }\end{array}$ & \\
Animal group & E: experimental, C: control & Paired $t$ test \\
\hline Control saline, & E: $7.3 \pm 1.0 / 4.2 \pm 1.0$ & $\mathrm{i}: p<0.001$ \\
$n=7$ & C: $17.7 \pm 1.1 / 0.3 \pm 0.1$ & f: $p<0.01$ \\
-6 hr CHX, & E: $9.2 \pm 1.5 / 2.1 \pm 0.3$ & $\mathrm{i}: p<0.02$ \\
$n=8$ & C: $11.8 \pm 1.6 / 1.3 \pm 0.2$ & f: $p<0.05$ \\
-2 hr CHX, & E: $8.7 \pm 1.3 / 1.5 \pm 0.3$ & i: $p<0.01$ \\
$n=5$ & C: $11.3 \pm 1.1 / 1.0 \pm 0.1$ & n.s. \\
0 hr CHX, & E: $7.1 \pm 1.1 / 2.7 \pm 0.9$ & i: $p<0.001$ \\
$n=6$ & C: $19.0 \pm 0.5 / 0.3 \pm 0.1$ & f: $p<0.05$ \\
$2 \mathrm{hr}$ CHX, & E: $6.6 \pm 0.8 / 4.0 \pm 0.6$ & i: $p<0.002$ \\
$n=8$ & C: $15.6 \pm 1.4 / 1.3 \pm 0.2$ & f: $p<0.005$
\end{tabular}

Mean initial EPSP amplitudes were measured prior to the onset of $30 \mathrm{~min}$ of 5 $\mathrm{Hz}$ test stimulation of the phasic axon, while mean final EPSP amplitudes were measured at the end of $5 \mathrm{~Hz}$ test stimulation. A paired $t$ test was used to compare the mean initial or final EPSP amplitude of experimental claws with the corresponding mean EPSP amplitude of contralateral control claws within each group. $i$, initial; $f$, final. here. The injection schedule for these experiments was identical to that used subsequently for experiments on LTA expression.

Collectively, these control experiments strongly suggest that $\mathrm{CHX}$, at the dosages used here, did not significantly alter the physiological response properties of the phasic motoneuron's neuromuscular synapses, as measured by intracellular recordings of evoked EPSPs. Furthermore, injected animals displayed no consistent behavioral changes under the conditions employed here. Since injected CHX had no effect on the expression of LFD, HFD, and LTF, these results are consistent with the hypothesis that expression of these phenomena is independent of protein synthesis and primarily dependent on temperaturesensitive, ion-dependent processes localized within the axon terminals of the phasic motoneuron (Pahapill et al., 1987).

\section{Effects of CHX on expression of LTA}

To determine whether full expression of LTA required protein synthesis within a discrete time period relative to each chronic stimulation period, we injected $5 \mu \mathrm{g} / \mathrm{gm} \mathrm{CHX}$ into intact crayfish before, during, or after each stimulation period. All animals were stimulated for 3 consecutive days, and claws were removed $2 \mathrm{~d}$ following chronic stimulation for EPSP measurements.

In a group of 7 saline-injected animals, the initial EPSP amplitude was significantly smaller in stimulated claws $(7.3 \pm 1.0$ $\mathrm{mV})$ than in contralateral unstimulated claws $(17.7 \pm 1.1 \mathrm{mV}$, $p<0.001$ for a paired $t$-test; Fig. $5 A$ ). Final EPSPs were significantly larger in stimulated claws $(4.2 \pm 1.0 \mathrm{mV})$ than in unstimulated claws $(0.3 \pm 0.1 \mathrm{mV}, p<0.01$; Fig. $5 A)$. Depression after $30 \mathrm{~min}$ of $5 \mathrm{~Hz}$ stimulation was significantly less in stimulated (depression index $0.46 \pm 0.12$ ) than in unstimulated claws $(0.98 \pm 0.01, p<0.05)$. The mean change in initial EPSP amplitude was $-10.4 \pm 1.5 \mathrm{mV}$ (reduction in amplitude), while that of the final EPSP amplitude was $3.9 \pm 0.9 \mathrm{mV}$ (Fig. 7). Thus, a 3-d stimulation regimen produced a robust expression of LTA that was evident $2 \mathrm{~d}$ after stimulation.

Injection of $\mathrm{CHX} 6 \mathrm{hr}$ prior to the onset of each stimulation period ( $-6 \mathrm{hr}$ CHX) did not block LTA completely. Initial EPSP amplitudes were significantly smaller in stimulated claws than in contralateral unstimulated claws $(p<0.02, n=8$; Table 1 
B

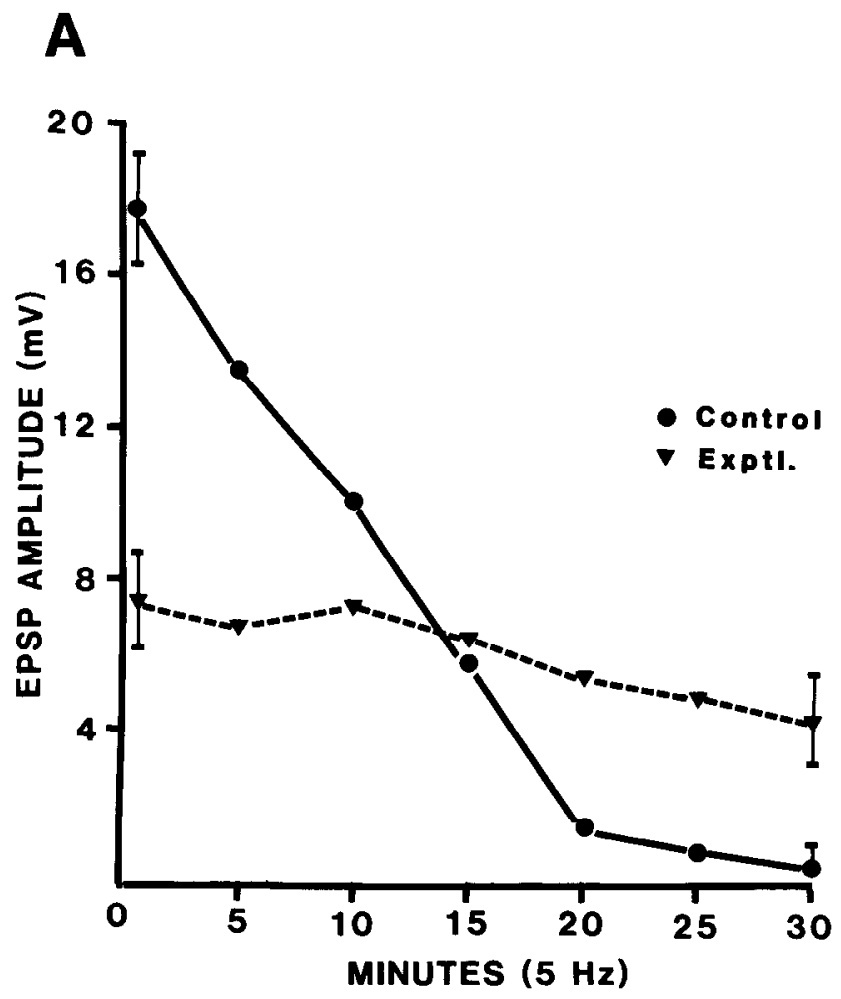

\section{Experimental}

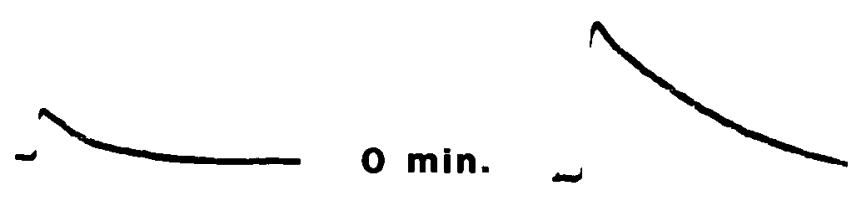

10

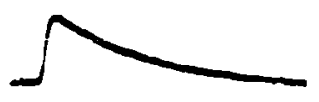

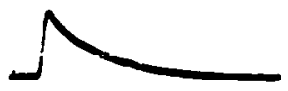

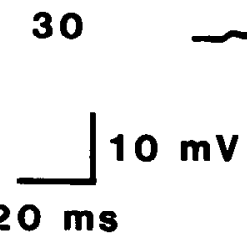

Figure 5. Long-term neuronal adaptation (LTA). A, Three days of chronic in vivo stimulation of the claw's phasic axon at $5 \mathrm{~Hz}(2 \mathrm{hr} / \mathrm{d}) \mathrm{produced}$ significant reductions in initial EPSP amplitudes $(0 \mathrm{~min})$ and synaptic depression in stimulated claws (triangles, "experimental") as compared to contralateral unstimulated claws (circles, "control"). EPSPs were measured $2 \mathrm{~d}$ after the last stimulation period. An identical stimulation schedule was used for subsequent LTA experiments. $n=7$ animals for this control group. $B$, Representative EPSP traces measured from experimental and control claws of a single animal during $5 \mathrm{~Hz}$ test stimulation of the phasic axon. The initial EPSP $(0 \mathrm{~min})$ was significantly smaller in the experimental claw, while the final EPSP $(30 \mathrm{~min})$ was significantly larger. The latter is indicative of increased resistance to synaptic depression in the experimental claw.

and Fig. 6A), while final EPSPs were significantly larger in stimulated claws than in unstimulated claws $(p<0.05)$. However, the magnitude of LTA was significantly attenuated, since the mean changes in initial and final EPSP amplitudes were significantly smaller than those of the control group (Fig. 7). The mean depression index of stimulated claws was significantly lower $(0.70 \pm 0.06)$ than that of unstimulated claws $(0.87 \pm$ $0.03, p<0.02$ ), while the former index was markedly, though not significantly, higher than the mean depression index of stimulated claws in the control group.

Injection of $\mathrm{CHX} 2 \mathrm{hr}$ prior to stimulation ( $-2 \mathrm{hr} \mathrm{CHX}$ ) also did not abolish LTA, since initial EPSPs were significantly smaller in stimulated claws $(p<0.01, n=5)$ than in unstimulated claws (Fig. $6 B$ and Table 1), while final EPSPs were not significantly larger in stimulated claws ( $p>0.05$; Fig. $6 B$ and Table 1). However, LTA was significantly attenuated compared to the control group, since mean changes in initial and final EPSPs were significantly smaller for this $-2 \mathrm{hr}$ CHX group (Fig. 7). Depression in stimulated claws was significantly greater $(0.81$ $\pm 0.04)$ than the depression in stimulated claws of the control group ( $p<0.05$ ), but was less than the depression observed in contralateral unstimulated claws $(0.91 \pm 0.02, p<0.05$ for a paired $t$ test).

For 6 animals injected at the onset of stimulation ( $0 \mathrm{hr} \mathrm{CHX})$, initial and final EPSPs were significantly smaller and larger, respectively, in stimulated claws when compared to unstimulated claws (Table 1 and Fig. 6C). Mean changes in initial and final EPSPs were not significantly different from those of the control group (Fig. 7; compare Figs. $5 \mathrm{~A}$ and $6 \mathrm{C}$ ). Depression was significantly less in stimulated claws $(0.61 \pm 0.13)$ than in contralateral unstimulated claws $(0.98 \pm 0.01, p<0.05)$ and was not significantly different from depression of stimulated claws in the control group ( $p>0.2$ ). Thus, LTA was fully expressed when CHX was administered at the onset of each chronic stimulation period.

Injection of $\mathrm{CHX}$ at the end of each 2-hr stimulation period ( $2 \mathrm{hr}$ CHX) also did not affect expression of LTA. Initial and final EPSPs were significantly smaller and larger, respectively, in stimulated claws $(n=8)$ compared to contralateral unstimulated claws (Fig. $6 D$ and Table 1). Mean changes in initial and final EPSPs were not significantly different from those of the control group (Fig. 7; compare Figs. 5A and 6D). Depression in stimulated claws $(0.42 \pm 0.07)$ was significantly less than that of contralateral unstimulated claws $(0.91 \pm 0.02, p<0.001)$, but was not significantly different from depression in the control group of animals $(p>0.5)$.

Overall, these experiments revealed that inhibition of protein synthesis prior to each stimulation period attenuated the expres- 
Figure 6. Effects of protein synthesis inhibition on LTA. $A$ and $B$. Injection of $5 \mu \mathrm{g} / \mathrm{gm} \mathrm{CHX}$ into intact crayfish 6 hr $(-6 h r C H X, n=8)$ or $2 \mathrm{hr}(-2 h r$ $C H X, n=5$ ) prior to each stimulation period significantly attenuated both the reduction in initial EPSP amplitudes and the elevation in final EPSP amplitudes normally expressed in neuronal LTA (compare with Fig. $5 A$ ). $C$ and $D$, Injection of $5 \mu \mathrm{g} / \mathrm{gm} \mathrm{CHX}$ at the onset of ( $0 \mathrm{hrCHX}, n=6)$ or at the end of ( $2 h r C H X, n=8$ ) each stimulation period did not affect expression of LTA. Initial EPSPs were significantly smaller and final EPSPs significantly larger in experimental claws as compared to contralateral control claws. All EPSPs were recorded $2 \mathrm{~d}$ after a $3-\mathrm{d}$ chronic stimulation regimen.

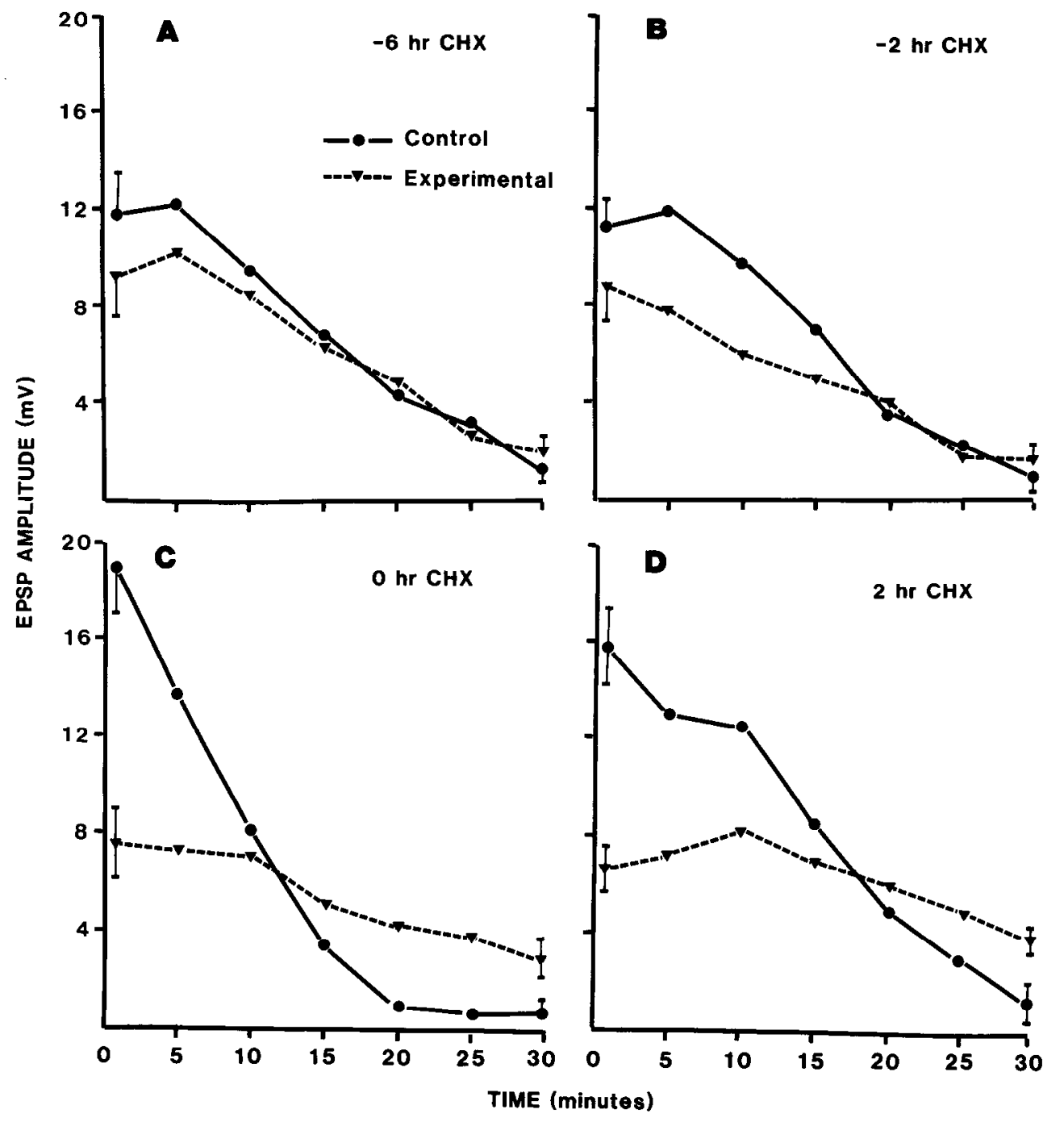

sion of LTA. Maximal inhibition of protein synthesis during or soon after each stimulation period failed to affect expression of LTA.

\section{Discussion}

Numerous studies have focused on the causative links between changes in neuronal protein synthesis and certain forms of longterm, activity-induced modifications of synaptic transmission, including mammalian hippocampal long-term potentiation (LTP) (Stanton and Sarvey, 1984; Deadwyler et al., 1987; reviewed by Sarvey, 1988) and long-term sensitization (LTS) in Aplysia (Montarolo et al., 1986; Dale et al., 1987; Castellucci et al., 1988, 1989; Schacher et al., 1988). A particularly common approach has been to apply protein synthesis inhibitors at specific times relative to periodic stimulation of an identified neuron.

It is clear from the functional diversity and ubiquity of neuronal proteins (Reichardt and Kelly, 1983) that a general inhibition of protein synthesis would inevitably perturb a number of intracellular protein-dependent processes, such as axonal transport, transmitter synthesis and mobilization, ion-channel functions, and enzyme-regulated metabolic processes. The specificity of action of protein synthesis inhibitors must be critically examined in the context of purported cause-effect relationships between protein synthesis inhibition and an observed alteration of synaptic efficacy.

The issue of nonspecific effects of $\mathrm{CHX}$ has been raised on numerous occasions (Flexner et al., 1973; Flexner and Goodman, 1975; Quartermain, 1976). CHX and other inhibitors of translation have been shown to produce anesthetic effects on sympathetic ganglia (Paggi and Toschi, 1971) and to depress hippocampal spike amplitudes (Stanton and Sarvey, 1984). Conversely, CHX does not impair axonal transport of proteins already situated within axons (McEwen and Grafstein, 1968; Ochs et al., 1970; Edstrom and Mattson, 1972; Buresova and Tucek, 1977) and selectively attenuates long-term memory in a highly dose-dependent manner that is tightly correlated with degrees of protein synthesis inhibition and memory impairment (Quinton and Kramarcy, 1977).

Although our results do not rule out nonspecific effects of $\mathrm{CHX}$, they do strongly suggest that the observed attenuation of LTA was not due to significant nonspecific effects of CHX. The selective attenuation of LTA within a discrete time window of protein synthesis inhibition, the dose-dependent, reversible blockade of [ $\left.{ }^{35} \mathrm{~S}\right]-$ Met incorporation, and the absence of detectable side effects of CHX on evoked EPSPs generated by the 


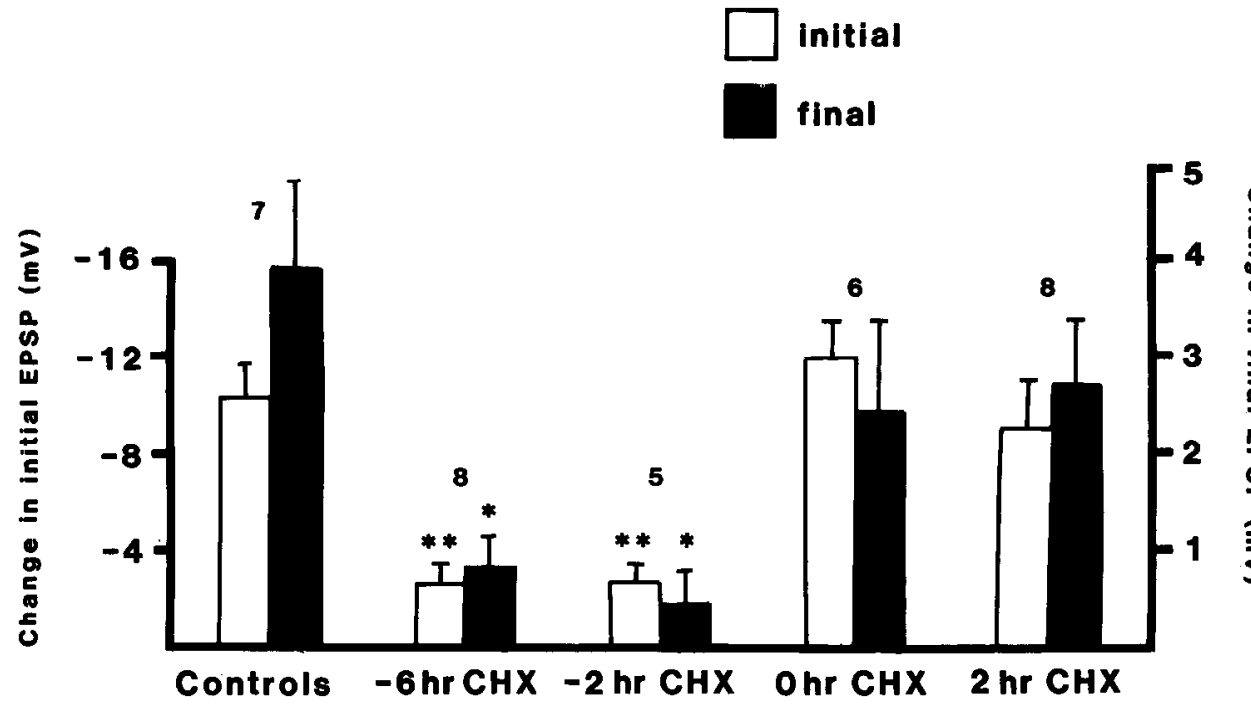

Figure 7. Summary of CHX and LTA data. The change in initial (or final) EPSP amplitude was calculated for each animal within each group as the difference between the initial (or final) EPSP amplitude in the stimulated claw and that of the contralateral unstimulated claw. "Controls" consisted of stimulated, saline-injected animals (see Fig. 5). Injection of $\mathrm{CHX} 6 \mathrm{hr}(-6 \mathrm{hrCHX})$ or $2 \mathrm{hr}(-2 \mathrm{hr} C H X)$ prior to each stimulation period significantly attenuated both the reduction in initial EPSPs (lefthand ordinate, open bars) and the elevation in final EPSPs (right-hand ordinate, black bars). Injection of CHX at the onset of $(0 \mathrm{hrCHX})$ or at the end of ( $2 \mathrm{hr} C H X)$ each stimulation period did not affect the changes in EPSP amplitudes produced by chronic stimulation. Numbers above bars are numbers of animals per group. ${ }^{*} p<0.02,{ }^{* *} p$ $<0.002$ for an unpaired $t$ test comparison of corresponding changes in EPSPs between the control group and each CHX-injected group. specific neuron of interest, all constitute strong evidence against a major causative role for gross nonspecific effects.

Our drug control experiments have established that neither chronic nor acute administration of $\mathrm{CHX}$ to intact animals and isolated claws, respectively, exerted harmful effects on the phasic motoneuron's transmitter-releasing capacity, as measured by the time course and magnitude of evoked EPSPs. Although CHX exerted minimal side effects on EPSPs under the conditions employed here, the time of data sampling may be critical to the outcome of these controls. We stress, however, that $\mathrm{CHX}$ exerted no detectable effects on evoked EPSPs in animals that had undergone an injection schedule identical to that used for our experiments on LTA expression. Furthermore, the $0.6 \mathrm{~mm}$ $\mathrm{CHX}$ concentration, used here to test for harmful side effects on neuromuscular synapses of preincubated isolated claws, was comparable to concentrations of other protein synthesis inhibitors known to produce rapid depression of EPSPs in isolated crayfish neuromuscular preparations (Onodera and Takeuchi, 1977) and depression of calcium currents in mouse motor synapses (Bourret and Mallart, 1989). The former has been attributed to interference with postsynaptic ion channel conductances (Onodera and Takeuchi, 1977). Although our studies do not rule out effects of $\mathrm{CHX}$ on postsynaptic muscle fiber input resistance, it is unlikely that significant changes in the latter occurred under our conditions, since we observed no significant changes in EPSP waveforms.

The results of the present experiments on LTA expression suggest that a pool of preexisting, short-lived proteins is required for full expression of LTA. The results also argue against the activity-induced synthesis of novel proteins as being critical for neuronal LTA. If the latter were true, then inhibition of protein synthesis during or after stimulation would have blocked LTA. Instead, the observed attenuation of LTA occurred only when protein synthesis was inhibited well before the onset of stimulation, suggesting that $\mathrm{CHX}$ depleted a pool of preexisting proteins critical for LTA. That these proteins may be short-lived derives from the observation that maximal inhibition of protein synthesis for a mere $2 \mathrm{hr}$ was sufficient to attenuate LTA. These results are similar to those of Deadwyler et al. (1987), in which hippocampal LTP was blocked by exposure to protein synthesis inhibitors for $30 \mathrm{~min}$, but not $15 \mathrm{~min}$, prior to induction. These authors also proposed that a preexisting pool of proteins was critical for expression of LTP.

The dynamic role of the synapse in information transfer demands that replenishment of structural and functional proteins, consumed during normal and imposed activity, occurs efficiently in a manner that is responsive to a neuron's activity level. The vast majority of synaptic proteins are supplied to the terminals via fast axonal transport, following their synthesis in the cell body (Cuenod et al., 1972; Droz, 1973; Krygier-Brevart et al., 1974). Such proteins have half-lives ranging from hours to weeks (Droz, 1973), with many turning over in relatively short periods of time (Droz and Leblond, 1963; Blomstrand and Hamberger, 1969). Rapid protein turnover might correlate with the high levels of lysosomal proteases observed in motoneurons (Hirsch and Parks, 1973; Hirsch, 1976). Furthermore, neuronal depolarization may increase the degradation of fast axonally transported proteins in nerve terminals via calcium-activated proteases (Sandberg et al., 1980; Kanje et al., 1985) and may subsequently modify the axonal transport rates of such proteins in an adaptive fashion (Jasmin et al., 1988).

The ability to prevent full expression of neuronal LTA through inhibition of protein synthesis occurring within a critical time window is consistent with previous studies suggesting a critical role for the phasic motoneuron's cell body in LTA expression. Axotomized motoneurons do not show LTA when chronic stimulation is applied in vivo to the surviving peripheral axonal segments (Lnenicka and Atwood, 1985b), while depolarization of the intact motoneuron per se is sufficient to induce LTA (Lnenicka and Atwood, 1988). The former observation also suggests that glial protein synthesis and transfer of glial proteins to axons (Lasek et al., 1977; Sheller et al., 1985) probably are not critically involved in LTA expression. Although we have not directly confirmed that protein synthesis is inhibited specifically in the claw's phasic motoneuron, it would be difficult to reconcile the present results with those of previous studies 
without assuming that such inhibition of neuronal protein synthesis indeed occurred under our conditions.

In contrast to studies on LTS in Aplysia, where critical changes in protein synthesis occurring during and shortly after induction are implicated (Goelet et al., 1986; Montarolo et al., 1986; Castellucci et al., 1988, 1989), our results on neuronal LTA suggest a permissive function for the putative preexisting proteins involved in LTA. Such proteins may be short-lived translational or transcriptional regulatory factors (Gokal et al., 1986), secondmessenger-associated enzymes (Bray et al., 1971), or axonal transport proteins (Buresova and Tucek, 1977). Depletion of these permissive proteins could preclude the operation of those intracellular biochemical processes necessary for expression of LTA and dependent on the availability of these permissive proteins.

The increased resistance to synaptic depression observed in adapted phasic motoneurons may be linked to the increased volume and branching of terminal mitochondria observed in earlier studies on LTA (Lnenicka et al., 1986). The increased mitochondrial volume might be indicative of an activity-induced increase in oxidative enzyme activity (Wong-Riley, 1989). Since transmitter mobilization is an energy-dependent process, increased activity of oxidative enzymes might better adapt a neuron to meet the increased energy requirements concomitant with an increased frequency of synaptic transmitter release (Sickles and Oblak, 1984).

The reduction in initial transmitter release associated with LTA is clearly presynaptic in origin (Lnenicka and Atwood, 1985a; Mercier and Atwood, 1989) and may be linked to reductions in the size and/or number of active release sites (Govind and Chiang, 1979; Atwood and Marin, 1983). Such reductions may be concomitant with activity-induced nerve terminal retraction (Jans et al., 1986; Wernig and Herrera, 1986). Indeed, prolonged stimulation of the crayfish phasic claw motoneuron also is associated with terminal retraction (G. A. Lnenicka, personal communication). Other possible mechanisms might involve down-regulation of calcium channels in the vicinity of relcase sites ( $c f$. Willow et al., 1986) or increased calcium buffering by mitochondria.

In general, both central and peripheral synapses may adapt to chronic changes in their activity levels. LTA at crayfish neuromuscular synapses may represent just one example of an activity-regulated, adaptive form of long-term synaptic plasticity. This is supported by the presence of long-lasting adaptive changes (consistent with those observed in crayfish) at central synapses of other species, including the cricket (Murphey and Matsumoto, 1976) and locust (Bloom and Atwood, 1981), and at vertebrate neuromuscular junctions (Robbins and Fischbach, 1971; Hinz and Wernig, 1988) and spinal cord (Gallego et al., 1979; Manabe et al., 1989). Although the molecular mechanisms underlying neuronal LTA remain undetermined, the recent discovery that LTA may be induced in a crayfish abdominal motoneuron (Mercier and Atwood, 1989) might provide a more accessible preparation for the study of such mechanisms.

\section{References}

Atwood, H. L. (1973) Crustacean motor units. In Control of Posture and Locomotion, R. B. Stein et al., eds., pp. 87-104, Plenum, New York.

Atwood, H. L. (1976) Organization and synaptic physiology of crustacean neuromuscular systems. Prog. Neurobiol. 7: 291-391.

Atwood, H. L., and L. Marin (1983) Ultrastructure of synapses with different transmitter-releasing characteristics on motor axon terminals of a crab, Hyas areneas. Cell Tiss. Res. 231: 103-115.

Atwood, H. L., and J. M. Wojtowicz (1986) Short-term and long-term plasticity and physiological differentiation of crustacean motor synapses. Int. Rev. Neurobiol. 28: 275-362.

Blomstrand, C., and A. Hamberger (1969) Protein turnover in cell enriched fractions from rabbit brain. J. Ncurochem. 16: 1401-1407.

Bloom, J. W., and H. L. Atwood (1981) Effects of altered sensory experience on the responsiveness of the locust descending contralateral movement detector neuron. J. Comp. Physiol. 135A: 191-199.

Bourret, C., and A. Mallart (1989) Depression of calcium current at mouse motor nerve endings by polycationic antibiotics. Brain Res. 478: 403-406.

Bradford, M. M. (1976) A rapid and sensitive method for the quantitation of microgram quantities of protein utilizing the principle of protein-dye binding. Anal. Biochem. 72: 248-254.

Bray, J. J., C. M. Kon, and B. M. Breckenridge (1971) Adenyl-cyclase, cyclic nucleotide phosphodiesterase and axoplasmic flow. Brain Res. 26: 385-394.

Buresova, M., and S. Tucek (1977) Cessation of axonal transport of acetylcholinesterase after administration of cycloheximide. Brain Res. 124: 379-384.

Castellucci, V. F., T. E. Kennedy, E. R. Kandel, and P. Goelet (1988) A quantitative analysis of 2-D gels identifies proteins in which labeling is increased following long-term sensitization in Aplysia. Neuron 1 : $321-328$.

Castellucci, V. F., H. Blumenfeld, P. Goelet, and E. R. Kandel (1989) Inhibitor of protein synthesis blocks long-term behavioral sensitization in the isolated gill-withdrawal reflex of Aplysia. J. Neurobiol. 20: $1-9$.

Cuenod, M., J. Boesch, P. Marko, M. Perisic, C. Sandri, and J. Schonbach (1972) Contributions of axoplasmic transport to synaptic structures and functions. Int. J. Neurosci. 4: 77-87.

Dale, N., E. R. Kandel, and S. Schacher (1987) Serotonin produces long-term changes in the excitability of 1 plysia sensory neurons in culture that depend on new protein synthesis. J. Neurosci. 7: 22322238.

Deadwyler, S. A., T. Dunwiddie, and G. Lynch (1987) A critical level of protein synthesis is required for long-term potentiation. Synapse I: $90-95$.

Droz, B. (1973) Renewal of synaptic proteins. Brain Res. 62: 383394.

Droz, B., and C. P. Leblond (1963) Axonal migration of proteins in the CNS and peripheral nerves as shown by radioautography. J. Comp. Neurol. I21:325-346.

Edstrom, A., and H. Mattson (1972) Rapid axon transport in vitro in the sciatic system of the frog of fucose-, glucosamine-, and sulfatecontaining material. J. Neurochem. 19: 1717-1729.

Flexner, L. B., and R. H. Goodman (1975) Studies on memory: Inhibitors of protein synthesis also inhibit catecholamine synthesis. Proc. Natl. Acad. Sci. USA 72: 4660-4663.

Flexner, L. B., R. G. Serota, and R. H. Goodman (1973) Cycloheximide and acetoxycycloheximide: Inhibition of tyrosine hydroxylase activity and amnestic effects. Proc. Natl. Acad. Sci. USA 70: 354356.

Freifelder, D. (1982) Physical Biochemistry, 2nd ed., Freeman, San Francisco.

Gallego, R., M. Kuno, R. Nunez, and W. D. Snider (1979) Disuse enhances synaptic efficacy in spinal motoneurons. J. Physiol. (Lond.) 291: 191-205.

Goelet, P., V. F. Castellucci, S. Schacher, and E. R. Kandel (1986) The long and the short of long-term memory: A molecular framework. Nature 322: 419-422.

Gokal, P. K., A. H. Cavanaugh, and E. A. Thompson Jr. (1986) The effects of cycloheximide upon transcription of rRNA, 5S RNA, and tRNA genes. J. Biol. Chem. 261: 2536-2541.

Govind, C. K., and R. G. Chiang (1979) Correlation between presynaptic dense bodies and transmitter output at lobster neuromuscular terminals by serial section electron microscopy. Brain Res. 161:377388.

Hinz, I., and A. Wernig (1988) Prolonged nerve stimulation causes changes in transmitter release at the frog neuromuscular junction. J. Physiol. (Lond.) 401: 557-565.

Hirsch, H. E. (1976) The chemistry of motor neurons: Research strategies. UCLA Forum Med. Sci. 19: 87-99. 
Hirsch, H. E., and M. E. Parks (1973) The quantitative histochemistry of acid proteinase in the nervous system: Localization in neurons. $\mathbf{J}$. Neurochem. 21: 453-458.

Jans, H., R. Salzmann, and A. Wernig (1986) Sprouting and nerve retraction in frog neuromuscular junction during ontogenesis and environmental changes. Neuroscience 18: 773-781.

Jasmin, B. J., P.-A. Lavoie, and P. F. Gardiner (1988) Fast axonal transport of labeled proteins in motoneurons of exercised-trained rats. Am. J. Physiol. 255: C731-C736.

Kanje, M., J. Lazarewicz, P. Ekstrom, and A. Edstrom (1985) Calciumactivated protease activity in frog sciatic nerve: Characterization and effect on rapidly transported axonal proteins. Brain Res. 327: 29-36.

Krygier-Brevart, V., D. G. Weiss, E. Mehl, P. Schubert, and G. W. Kreutzberg (1974) Maintenance of synaptic membranes by the fast axonal flow. Brain Res. 77: 97-110.

Lasek, R. J., H. Gainer, and J. L. Barker (1977) Cell-to-cell transfer of glial proteins to the squid giant axon. J. Cell Biol. 74: 501-523.

Lnenicka, G. A., and H. L. Atwood (1985a) Age-dependent long-term adaptation of crayfish phasic motor axon synapses to altered activity. J. Neurosci. 5: 459-467.

Lnenicka, G. A., and H. L. Atwood (1985b) Long-term facilitation and long-term adaptation at synapses of a crayfish phasic motoneuron. J. Neurobiol. 16:97-110.

Lnenicka, G. A., and H. L. Atwood (1988) Long-term changes in neuromuscular synapses with altered sensory input to a crayfish motoneuron. Exp. Neurol. 100: 437-447.

Lnenicka, G. A., H. L. Atwood, and L. Marin (1986) Morphological transformation of synaptic terminals of a phasic motoneuron by longterm tonic stimulation. J. Neurosci. 6: 2252-2258.

Manabe, T., S. Kaneko, and M. Kuno (1989) Disuse-induced enhancement of Ia synaptic transmission in spinal motoneurons of the rat. J. Neurosci. 9: 2455-2461.

Martin, A. R. (1955) A further study of the statistical composition of the end-plate potential. J. Physiol. (Lond.) 130: 114-122.

McEwen, B. S., and B. Grafstein (1968) Fast and slow components in axonal transport of protein. J. Cell Biol. 38: 494-508.

Mercier, A. J., and H. L. Atwood (1989) Long-term adaptation of a phasic extensor motoneuron in crayfish. J. Exp. Biol. 145: 9-22.

Montarolo, P. G., P. Goelet, V. F. Castellucci, J. Morgan, E. R. Kandel, and S. Schacher (1986) A critical time period for macromolecular synthesis in long-term heterosynaptic facilitation in Aplysia. Science 234: 1249-1254.

Murphey, R. K., and S. G. Matsumoto (1976) Experience modifies the plastic properties of identified neurons. Science 191: 564-566.

Ochs, S., M. I. Sabri, and N. Ranish (1970) Somal site of synthesis of fast transported materials in mammalian nerve fibres. J. Neurobiol. 1: $329-344$.

Onodera, K., and A. Takeuchi (1975) Ionic mechanism of the excitatory synaptic membrane of the crayfish neuromuscular junction. $J$. Physiol. (Lond.) 252: 295-318.

Onodera, K., and A. Takeuchi (1977) Inhibitory effect of streptomycin and related antibiotics on the glutamate receptor of the crayfish neuromuscular junction. Neuropharmacology 16: 171-177.

Paggi, P., and G. Toschi (1971) Inhibitors of protein synthesis involved in memory disruption: A study of their effect on sympathetic ganglion isolated in vitro. J. Neurobiol. 2: 119-128.
Pahapill, P. A., G. A. Lnenicka, and H. L. Atwood (1987) Long-term facilitation and low-frequency depression in a crayfish phasic motor axon. J. Comp. Physiol. 161A: 367-375

Quartermain, D. (1976) The influence of drugs on learning and memory. In Neural Mechanisms of Learning and Memory, M. Rosenzweig and E. Bennett, eds., pp. 508-518, MIT Press, Cambridge, MA.

Quinton, E. E., and N. R. Kramarcy (1977) Memory impairment correlates closely with cycloheximide dose and degree of inhibition of protein synthesis. Brain Res. 131: 184-190.

Reichardt, L. F., and R. B. Kelly (1983) A molecular description of nerve terminal function. Annu. Rev. Biochem. 52: 871-926.

Robbins, N., and G. D. Fischbach (1971) Effect of chronic disuse of rat soleus neuromuscular junctions on presynaptic function. J. Neurophysiol. 34: 570-578.

Sandberg, M., A. Hamberger, I., Jacobson, and J.-O. Karlson (1980) Role of calcium ions in the formation and release of low-molecular substances from optic nerve terminals. Neurochem. Res. 5: 11851198.

Sarvey, J. M. (1988) Protein synthesis in long-term potentiation and norepinephrine-induced long-lasting potentiation in hippocampus. In Long-term Potentiation: From Biophysics to Behavior, P. W. Landfield and S. A. Deadwyler, eds., pp. 329-353, Liss, New York.

Schacher, S., V. F. Castellucci, and E. R. Kandel (1988) cAMP evokes long-term facilitation in Aplysia sensory neurons that requires new protein synthesis. Science 240: 1667-1669.

Sheller, R. A., K. R. Seshan, T. A. Viancour, and G. D. Bittner (1985) Intercellular transfer of horseradish peroxidase label in crayfish giant axons. Soc. Neurosci. Abstr. 11: 1148.

Sickles, D. W., and T. G. Oblak (1984) Metabolic variation among alpha-motoneurons innervating different muscle-fiber types. I. Oxidative enzyme activity. J. Neurophysiol. 51: 529-537.

Sisler, H. D., and M. R. Siegel (1967) Cycloheximide and other glutarimide antibiotics. In Antibiotics, Vol. I: Mechanism of Action, D. Gottlieb and P. D. Shaw, eds., pp. 283-307, Springer-Verlag, New York.

Stanton, P. K., and J. M. Sarvey (1984) Blockade of long-term potentiation in rat hippocampal CAl region by inhibitors of protein synthesis. J. Neurosci. 4: 3080-3088.

Van Harreveld, A. (1936) A physiological solution for freshwater crustaceans. Proc. Soc. Exp. Biol. Med. 34: 428-432.

Van Harreveld, A., and C. A. G. Wiersma (1936) The double motor innervation of the adductor muscle in the claw of the crayfish. $J$. Physiol. (Lond.) 88: 78-99.

Wernig, A., and A. A. Herrera (1986) Sprouting and remodelling at the nerve-muscle junction. Prog. Neurobiol. 27: 251-291.

Wettstein, F. O., H. Noll, and S. Penman (1964) Effect of cycloheximide on ribosomal aggregates engaged in protein synthesis in vitro. Biochim. Biophys. Acta 87: 525-528.

Willow, M., S. M. Taylor, W. A. Catterall, and R. H. Finnell (1986) Down regulation of sodium channels in nerve terminals of spontaneously epileptic mice. Cell. Mol. Neurobiol. 6: 213-220.

Wong-Riley, M. T. T. (1989) Cytochrome oxidase: An endogenous metabolic marker for neuronal activity. Trends Neurosci. 12:94-101. 